\title{
Commentary: "Magnetic resonance elastography can predict the development of hepatocellular carcinoma: a meta-analysis and systematic review"
}

\author{
Jiangfeng $\mathrm{Wu}^{\wedge}$, Yunpeng $\mathrm{Li}$, Zehao $\mathrm{Hu}$ \\ Department of Ultrasound, The Affiliated Dongyang Hospital of Wenzhou Medical University, Dongyang, China \\ Correspondence to: Jiangfeng Wu. Department of Ultrasound, The Affiliated Dongyang Hospital of Wenzhou Medical University, No. 60 Wuning \\ West Road, Dongyang 322100, China. Email: wjfhospital@163.com.
}

Submitted Oct 02, 2021. Accepted for publication Nov 24, 2021.

doi: 10.21037/jgo-21-646

View this article at: https://dx.doi.org/10.21037/jgo-21-646

We read with great interest the recent meta-analysis written by $\mathrm{Wu}$ and colleagues entitled "Magnetic resonance elastography can predict the development of hepatocellular carcinoma: a meta-analysis and systematic review" (1). The authors highlight magnetic resonance elastography (MRE) can be an effective diagnostic tool for hepatocellular carcinoma (HCC) and can provide strong support for the selection of clinical treatment methods and prognostic judgment. We strongly agree with the authors about the importance of the MRE, however, we have several comments on this article.

First, the meaning of the title is that MRE can predict the development of HCC, but, in this study, the authors aimed to evaluate the effectiveness of MRE in the diagnosis of HCC patients. Predicting the development of HCC and diagnosing HCC are two significantly different concepts. Therefore, we think the title of this article is not appropriate.

Second, this article is a systematic review and metaanalysis of diagnostic test accuracy studies; furthermore, true-positive, false-positive, false-negative, and truenegative values extracted for $2 \times 2$ contingency tables are one of the most important data (2). However, they were not referred to in this article. The risk ratio (RR) and mean difference (MD) were introduced in the statistics section of this paper. But, they are not suitable for a systematic review and meta-analysis of diagnostic test accuracy studies (2).

Third, the nine studies included in the heterogeneity assessment showed significant heterogeneity $\left(\mathrm{I}^{2}=92.44 \%\right.$ for sensitivity, $\mathrm{P}=0.00 ; \mathrm{I}^{2}=67.86 \%$ for specificity, $\mathrm{P}=0.00$ ).

Due to the significant heterogeneity, we think that metaregression and subgroup analyses should be performed to explore potential sources of heterogeneity. The covariates such as country (China versus Korea), year of publication (2016-2017 versus 2018-2020), and sample size (>150 versus $<150)$ might be taken into account when metaregression and subgroup analyses are carried out.

Fourth, in this study, the pooled sensitivity and specificity were estimated at $64 \%$ and $85 \%$, demonstrating that MRE has a high false-negative rate $(36 \%)$ and should not be used for exclusion of HCC. But, in conclusion, the author demonstrated that MRE imaging has moderate sensitivity and excellent specificity in the detection of HCC, and can be used as a recommended diagnostic technique for HCC. We think that the conclusion might be not rational. On the basis of the overall results, patients suspected of HCC should be referred to more sensitive and specific diagnostic modalities.

\section{Acknowledgments}

Funding: None.

\section{Footnote}

Provenance and Peer Review: This article was a standard

^ ORCID: 0000-0002-5036-799X. 
submission to the journal. The article has not undergone external peer review.

Conflicts of Interest: All authors have completed the ICMJE uniform disclosure form (available at https://dx.doi. org/10.21037/jgo-21-646). The authors have no conflicts of interest to declare.

Ethical Statement: The authors are accountable for all aspects of the work in ensuring that questions related to the accuracy or integrity of any part of the work are appropriately investigated and resolved.

Open Access Statement: This is an Open Access article distributed in accordance with the Creative Commons Attribution-NonCommercial-NoDerivs 4.0 International
License (CC BY-NC-ND 4.0), which permits the noncommercial replication and distribution of the article with the strict proviso that no changes or edits are made and the original work is properly cited (including links to both the formal publication through the relevant DOI and the license). See: https://creativecommons.org/licenses/by-nc-nd/4.0/.

\section{References}

1. Wu L, Bi J, Liu L, et al. Magnetic resonance elastography can predict the development of hepatocellular carcinoma: a meta-analysis and systematic review. J Gastrointest Oncol 2021;12:1215-22.

2. McInnes MDF, Moher D, Thombs BD, et al. Preferred Reporting Items for a Systematic Review and Metaanalysis of Diagnostic Test Accuracy Studies: The PRISMA-DTA Statement. JAMA 2018;319:388-96.
Cite this article as: $\mathrm{Wu} \mathrm{J}, \mathrm{Li} \mathrm{Y}, \mathrm{Hu} \mathrm{Z}$. Commentary: "Magnetic resonance elastography can predict the development of hepatocellular carcinoma: a meta-analysis and systematic review". J Gastrointest Oncol 2021;12(6):3163-3164. doi: 10.21037/ jgo-21-646 